\title{
Frequency of Shoulder Corticosteroid Injections for Pain and Stiffness After Shoulder Surgery and Their Potential to Enhance Outcomes with Physiotherapy: A Retrospective Study
}

\author{
John G. Skedros (D) Micheal G. Adondakis · Alex N. Knight • \\ Michael B. Pilkington
}

Received: December 19, 2016 / Published online: February 9, 2017

(C) The Author(s) 2017. This article is published with open access at Springerlink.com

\section{ABSTRACT}

Introduction: What is the rate of injecting patients with shoulder corticosteroid injections to alleviate excessive stiffness and pain within 6 months after shoulder surgery?

Methods: Retrospective 10-year review of a shoulder surgeon's practice. Participants included 754 patients who had 945 non-arthroplasty shoulder surgeries. Outcome measures included the rate of injections, diagnoses, patient characteristics, and efficacy via questionnaire.

Results: Approximately one in five patients received a subacromial and/or glenohumeral corticosteroid injection. Over $95 \%$ of patients stated that the injections helped reduce shoulder pain and increased function 6 weeks post-injection. Twenty-two percent of cases (208/945) received glenohumeral and/or subacromial injections. The 208 injected cases had these diagnoses: rotator cuff tear $(28 \%$ of injected patients), subacromial impingement

Enhanced content To view enhanced content for this article go to http://www.medengine.com/Redeem/ 5887F0607A2E9A9C.

J. G. Skedros ( $\square)$

Intermountain Medical Center and Utah

Orthopaedic Specialists, Salt Lake City, USA

e-mail: jskedrosmd@uosmd.com

M. G. Adondakis · A. N. Knight · M. B. Pilkington Utah Orthopaedic Specialists, Salt Lake City, USA
(20\%), glenohumeral instability (16\%), subacromial impingement with acromioclavicular osteoarthritis (10\%), adhesive capsulitis (7\%), SLAP lesion (5\%), biceps tendinopathy (3\%), glenohumeral instability with subacromial impingement (3\%), proximal humerus fracture $(2 \%)$, calcific tendinitis (2\%), and less common conditions (4\%). Diagnoses among those with the highest rates of injected patients per diagnosis included: SLAP lesions (40\%), calcific tendinitis (40\%), adhesive capsulitis (29\%), subacromial impingement $(28 \%)$, proximal humerus fracture $(24 \%)$, rotator cuff tear $(19 \%)$, and glenohumeral instability (16\%). Significant differences $(p<0.03)$ were found between patients who did and did not receive injections with respect to age (more likely younger patients with cuff tear) and sex (more likely female with subacromial impingement and instability) but not for diabetes or arthroscopic vs. open procedures.

Conclusion: This is the first study to establish the rates of postoperative shoulder corticosteroid injections within the first 6 months after various non-arthroplasty shoulder surgeries for patients with high pain/stiffness. These data will be useful for establishing guidelines for using corticosteroid injections along with physiotherapy.

Keywords: Corticosteroid injection; Shoulder pain; Shoulder stiffness; Shoulder surgery 


\section{INTRODUCTION}

Pain and stiffness are often concurrent problems that impede the recovery of patients who have had shoulder surgery despite being enrolled in a physiotherapy program. Surgeons commonly administer corticosteroid injections to help relieve the symptoms of these patients and aid their progression through physiotherapy, but this intervention has received little study, and the rationale for the use of these injections in the postoperative setting is largely based on anecdotal evidence. Our main goal of the present study is to establish our rates of administering postoperative corticosteroid injection treatments for our patients who had non-arthroplasty shoulder surgery. We will then use this information as baseline data for designing prospective randomized trials to assess their effectiveness when used in combination with physiotherapy to reduce shoulder stiffness and/or pain when compared to control and alternative treatment groups in the postoperative setting.

The high level of pain experienced by patients after the various types of shoulder surgeries is well documented. For example, a survey-based investigation of the severity of pain following ambulatory surgery in 5703 patients showed that 30\% (1712) experienced moderate-to-severe postoperative pain. In the patients with moderate-to-severe pain, $54 \%$ had shoulder surgeries [1]. Surgery for rotator cuff disease, subacromial impingement, glenohumeral instability, calcific tendinitis, and other common shoulder conditions or injuries can produce high and persistent pain levels that increase the probability of developing excessive postoperative stiffness in some patients [2-4]. While some reviews and meta-analyses show that there can be highly variable outcomes when subacromial and glenohumeral corticosteroid injections are used for alleviating pain and/or stiffness for certain common shoulder conditions [5-7], many studies support their continued use in this context [8-12].

In the first 10 years of his private practice, the senior author (JGS) and his colleagues published papers wherein they reviewed the literature on the varying effectiveness of these injections in addition to overviewing the indications, dosages, administration techniques, and appropriate use vs. misuse of corticosteroid injections in the treatment of various shoulder conditions [13-17]. However, we are not aware of any published studies that have investigated both the frequency with which corticosteroid injections are given and the specific conditions for which they are given within 6 months after non-arthroplasty shoulder surgeries.

In our study we focused on this question: What is the rate of injecting patients with shoulder corticosteroid injections to alleviate excessive stiffness and pain within 6 months after shoulder surgery? In this context, we hypothesized that postoperative corticosteroid injections for excessive pain and/or stiffness would be most commonly given in the following circumstances because of their propensity to result in excessive pain and/or stiffness: (1) after procedures for rotator cuff tears, shoulder instability, and calcific tendinitis [2, 18, 19], (2) in procedures for diabetic patients $[2,20]$, and (3) in open procedures when compared to arthroscopic procedures $[2,21]$.

\section{METHODS}

\section{Compliance with Ethics Guidelines}

This study was reviewed and approved by the Ethics Committee of Intermountain Healthcare (no. 1024079, Salt Lake City, UT, USA). All procedures followed were in accordance with the Helsinki Declaration of 1964, as revised in 2013. The analysis used anonymous clinical data that were obtained after each patient agreed to treatment by written consent. Because the study is retrospective, patients were not aware that data related to their treatment and management would be used for this study. For full disclosures, the details of the study are available from Intermountain Healthcare Institutional Review Board (see Data Availability section below). 


\section{Design}

We retrospectively reviewed medical records from a 10-year period (January 2002 to January 2012) from one surgeon's practice. During this period approximately $40-60 \%$ of the surgeries that the surgeon performed were for shoulder and elbow conditions or injuries.

\section{Participants}

The 754 patients included in this study had 945 shoulder surgeries that excluded arthroplasty. Table 1 shows the number and frequency of male, female, and all patients within each diagnostic/surgery group. We did not exclude patients from the study due to age or diabetes. Exclusion criteria included: revision shoulder surgery, fracture nonunion or pseudoarthrosis, stiffness caused by glenohumeral arthritis, shoulder arthrodesis, congenital disorders with impaired shoulder function, diagnostic shoulder arthroscopy, shoulder girdle motor control deficits, postoperative neurologic complication resulting in functional deficit of the shoulder, more than one operation on the same shoulder in the study period, previous shoulder arthroplasty, delayed wound healing, and infection or suspicion of infection.

We also examined medical records of the 945 surgical cases that met the inclusion criteria for corticosteroid injections given in the shoulder region during the 6 months following their shoulder surgery. The following information was recorded: patient age, sex, body mass index (BMI), diabetic history, medication use, and additional medical history (including thyroid dysfunction, Dupuytren's disease, cerebral vascular accident, myocardial infarction, cardiovascular disease, and breast cancer treatment) $[2,22]$.

After surgery the following data were recorded: type of operation, type of surgery (arthroscopic or open), dominant hand and right/left shoulder operated on, range of motion immediately before surgery, and septic, dermatological, or other complications spanning for up to 1 year after surgery.

After surgery all patients were allowed ad libitum use of oral NSAIDs as long as they were tolerated and not medically contraindicated. All patients received postoperative physiotherapy using standardized protocols [23]. After being discharged from formal physiotherapy, all patients continued a self-directed home physiotherapy program that continued for at least 6 months after their shoulder surgery.

\section{Intervention}

The senior author (JGS) administered all of the corticosteroid injections, which were given with the intent to alleviate excessive shoulder pain and/or stiffness within 6 months after his patient's shoulder surgeries. The decision to inject was based on patient-reported stiffness $(\leq 60 \%$ full motion in shoulder flexion or external rotation) and pain of at least moderate intensity with activities of daily living and during physiotherapy [24] as well as the patient's progress in physiotherapy and recovery thereafter. This approach reflected the surgeon's standard practice, which did not change during the 10-year study period.

Most patients who received an injection were placed into one of two general categories: (1) mostly pain of moderate-to-severe intensity during physiotherapy and (2) mostly stiffness, with pain being less than moderate during physiotherapy. A third category was created ("bursitis/inflammation") for patients who had, compared to the other two categories, pain that was more localized to the subacromial region.

All corticosteroid injections were administered freehand by the senior author without the use of fluoroscopy or any other image-guided technology. The injections were given into the subacromial (SA) space and/or the glenohumeral $(\mathrm{GH})$ joint. Whether one or both locations were injected depended on the senior author's examination and the specific location of the surgery [e.g., subacromial region vs. glenohumeral region (or both)]. If there was excessive stiffness $(\leq 60 \%$ full motion in shoulder flexion or external rotation), then both locations were injected. For all of the injections, the skin was first prepped with alcohol swabs and was allowed to dry. This was then followed by a povidone-iodine prep, which was also 


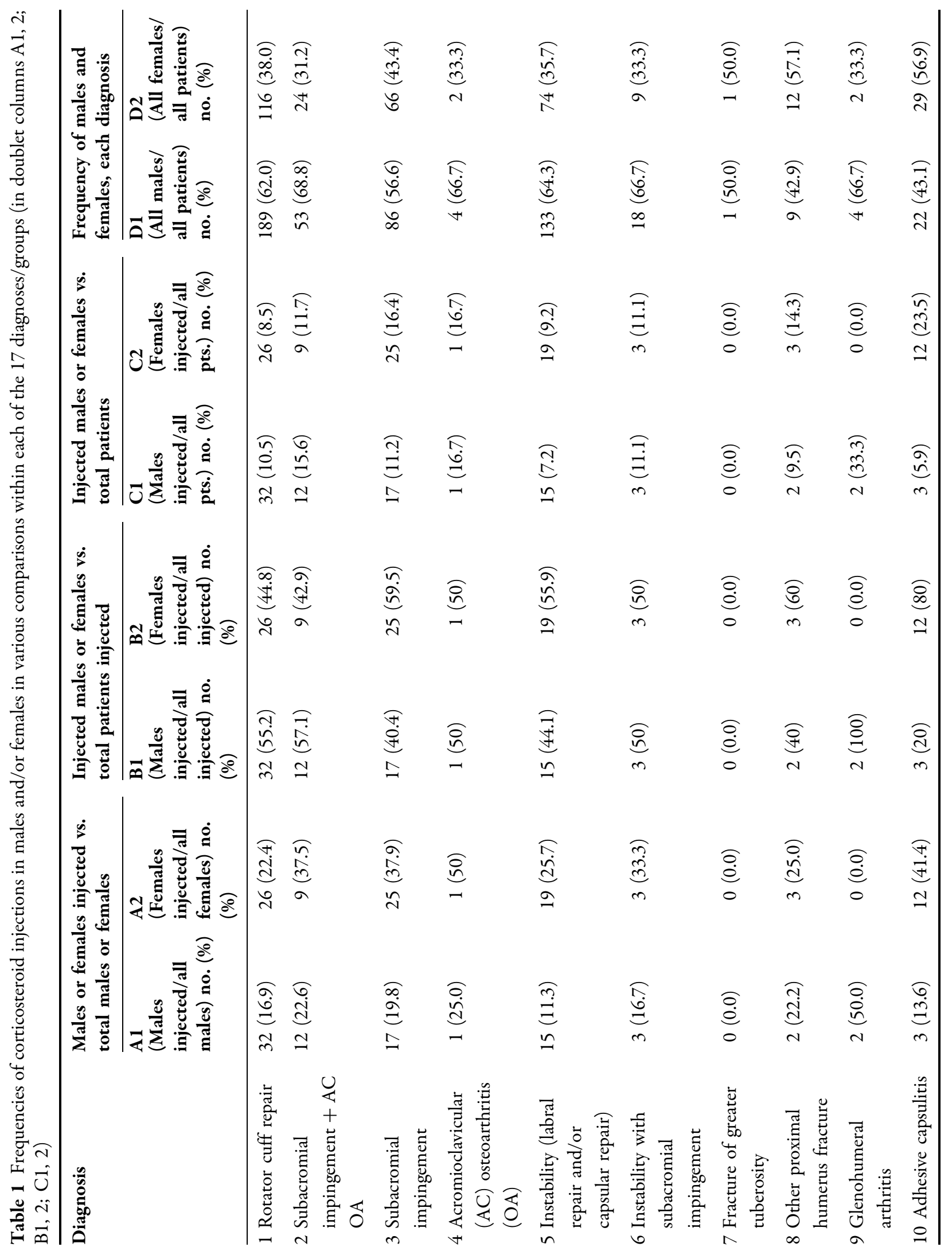




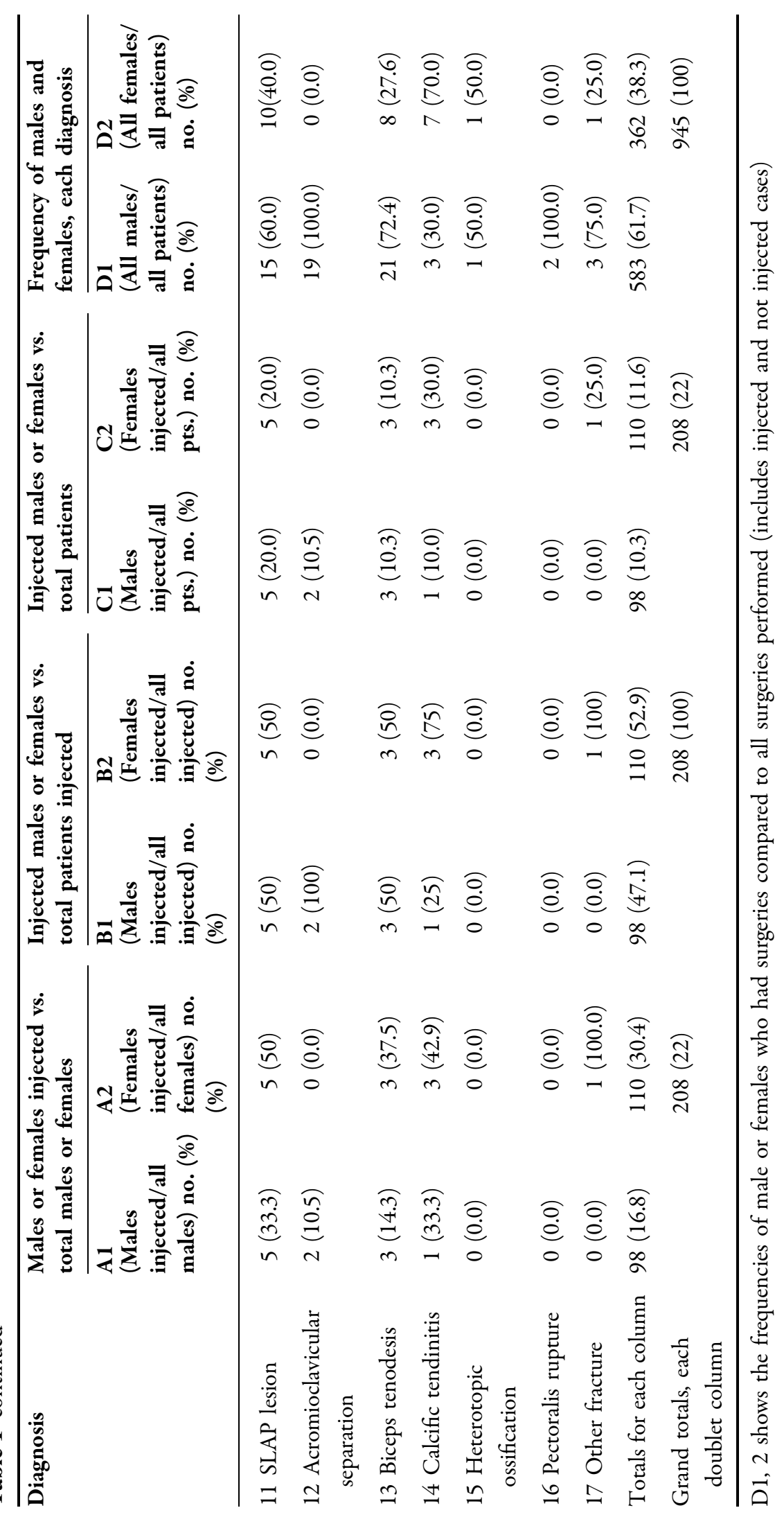


allowed to dry. Each injection included $4 \mathrm{cc}$ of $1 \%$ lidocaine and $80 \mathrm{mg}$ of methylprednisolone acetate (Depo-Medrol ${ }^{\circledR}$ injectable suspension; Pfizer Inc., NY, USA); the same amounts were used for the subacromial space and glenohumeral joint. Consequently, when both of these locations were injected, the patient received a total of $8 \mathrm{cc}$ of $1 \%$ lidocaine and $160 \mathrm{mg}$ of Depo-Medrol ${ }^{\circledR}$. These volumes are consistent with conventional practice [13]. Additional details of the injection techniques are described elsewhere [14].

\section{Outcome Measures}

The primary outcome measure in this study was the diagnosis, and consequently the type of surgery, for the patients who received shoulder corticosteroid injections within 6 months after surgery. Secondary outcomes included the patient characteristics, pain relief, and their overall assessment of how well the injections had helped them. After receiving their injections, the patients were seen in clinic at 4-6-week intervals for at least three additional visits. At each follow-up, the general effectiveness of the injection in facilitating patients' progress in physiotherapy and their general improvement in shoulder function were determined. Patients' appraisals of their improvement, failure to improve, or worsening pain and/or stiffness were obtained from their verbal reports and by a written report from their physiotherapist. The efficacy of the injections between the 4-6-week and 8-12-week follow-up visits was determined using patients' responses to a questionnaire regarding their general improvement in pain and function. The possible responses included: (1) worse, (2) not improved (but not worse), or (3) better. The latter group ("better") had three responses that were printed on a horizontal numerical scale with whole integers, as follows: mildly better $(1,2,3)$, moderately better $(4,5,6)$, or substantially better $(7,8,9,10)[24]$.

\section{Data Analysis}

Each shoulder surgery was studied as an independent entity. We used an analysis of variance
(ANOVA) design to analyze the data with respect to all patients (group 1) and if a patient received a corticosteroid injection (group 2) or did not receive a corticosteroid injection (group 3). Pairwise comparisons between the specific patient characteristics and types of surgery in group 2 and group 3 were then assessed for statistical significance using Fisher's PLSD post hoc test (Stat View Version 5.0, SAS Institute Inc., Cary, NC, USA). When data sets deviated from normality, paired comparisons were conducted using a Kruskal-Wallis $Z$ test $[25,26]$. The Wilcoxon-Mann-Whitney test was used for the ordered categorical options regarding patient-reported outcomes after the injection(s) [27]. An alpha level of $\leq 0.05$ is considered statistically significant.

\section{RESULTS}

Table 1 lists the shoulder diagnoses and the numbers and frequencies of male and/or female patients injected within each of the 17 diagnostic group/surgery groups. These data are expressed in terms of frequencies in various ways as shown in the column doublets (A1,2; $\mathrm{B} 1,2 ; \mathrm{C} 1,2)$. Table 1 also shows frequencies of surgeries performed for each sex, the number of male or female patients (injected and not injected) as a percentage of all surgeries performed, and the number of males and females injected as a percentage of total males and females for each of the 17 groups.

In the series of 945 total surgeries, there were 208 cases $(22 \%)$ where a shoulder corticosteroid injection was given within 6 months after surgery ( $88 \pm 38$ days after surgery; range $12-$ 184 days). Table 2 lists some of the patient characteristics and the four diagnoses that were hypothesized by the authors to be among those that had the highest percentage of patients who received a corticosteroid injection. Although we found that the rate of patients receiving injections in patients who had calcific tendinitis was the highest (40\%), there were only ten patients in this group. An equally high rate of injections (40\%) within each diagnostic/surgery group was also found in patients who had surgery for SLAP lesions ( $n=25$ patients), and all of these 
Table 2 Basic patient characteristics for all patients and the four diagnoses hypothesized by the authors to have the highest rate of injections

Shoulder corticosteroid injection groups [group size, means, and (standard deviations)]

\begin{tabular}{llll}
\hline 1 & 2 & 3 & $p$ value column 2 vs. 3 \\
All patients & Cortisone shot given & No cortisone shot given & \\
\hline
\end{tabular}

All shoulder surgeries

$\begin{array}{lllll}\text { Number } & 945 & 208(22 \%) & 737(78 \%) & - \\ \text { Age } & 48(16) & 46(14) & 48(16) & \text { ns } \\ \text { Sex } & 583 \mathrm{M} / 362 \mathrm{~F} & 98 \mathrm{M} / 110 \mathrm{~F} & 485 \mathrm{M} / 252 \mathrm{~F} & <0.001 \\ \text { BMI } & 29.2(6.0) & 28.7(6.1) & 29.3(5.9) & \mathrm{ns}\end{array}$

Rotator cuff repair

$\begin{array}{lll}\text { Number } & 305 & 58(19 \%) \\ \text { Age } & 57(13) & 53(13) \\ \text { Sex } & 189 \mathrm{M} / 116 \mathrm{~F} & 32 \mathrm{M} / 26 \mathrm{~F} \\ \text { BMI } & 30.5(6.2) & 29.5(7.3)\end{array}$

$247(81 \%)$

$58(12)$

0.009

Subacromial impingement

$\begin{array}{lll}\text { Number } & 152 & 42(28 \%) \\ \text { Age } & 47(14) & 45(14) \\ \text { Sex } & 86 \mathrm{M} / 66 \mathrm{~F} & 17 \mathrm{M} / 25 \mathrm{~F} \\ \text { BMI } & 29.2(5.7) & 28.3(6.0)\end{array}$

$157 \mathrm{M} / 90 \mathrm{~F}$

ns

$30.7(5.8)$

ns

Glenohumeral instability

\begin{tabular}{lllll} 
Number & 207 & $34(16 \%)$ & $173(84 \%)$ & - \\
Age & $35(12)$ & $35(12)$ & $35(13)$ & $\mathrm{ns}$ \\
Sex & $133 \mathrm{M} / 74 \mathrm{~F}$ & $15 \mathrm{M} / 19 \mathrm{~F}$ & $118 \mathrm{M} / 55 \mathrm{~F}$ & 0.03 \\
BMI & $27.5(5.7)$ & $27.1(4.9)$ & $27.5(5.9)$ & $\mathrm{ns}$ \\
Calcific tendinitis & & & \\
Number & 10 & $4(40 \%)$ & $6(60 \%)$ & - \\
Age & $46(13)$ & $52(19)$ & $42(7)$ & $\mathrm{ns}$ \\
Sex & $3 \mathrm{M} / 7 \mathrm{~F}$ & $1 \mathrm{M} / 3 \mathrm{~F}$ & $2 \mathrm{M} / 4 \mathrm{~F}$ & $\mathrm{~ns}$ \\
BMI & $32.1(9.2)$ & $29.9(6.0)$ & $33.9(11.5)$ & $\mathrm{ns}$ \\
\hline
\end{tabular}

Group $1=$ all patients, group $2=$ patients who received a corticosteroid injection, and group $3=$ patients who did not receive a corticosteroid injection

$M$ males, $F$ females, $n s$ non-significant $(p>0.05$; note that $p>0.1$ for all ns)

procedures were arthroscopic. Additionally, $29 \%$ of patients with adhesive capsulitis $(n=51)$ had injections. Other diagnoses with high rates of injections that are not shown in
Table 2 included isolated acromioclavicular arthritis, which only six patients within the diagnostic/surgery group had (33\%, two patients, injected), and patients who had 


\section{Percent of Injected Patients Based on Diagnosis}

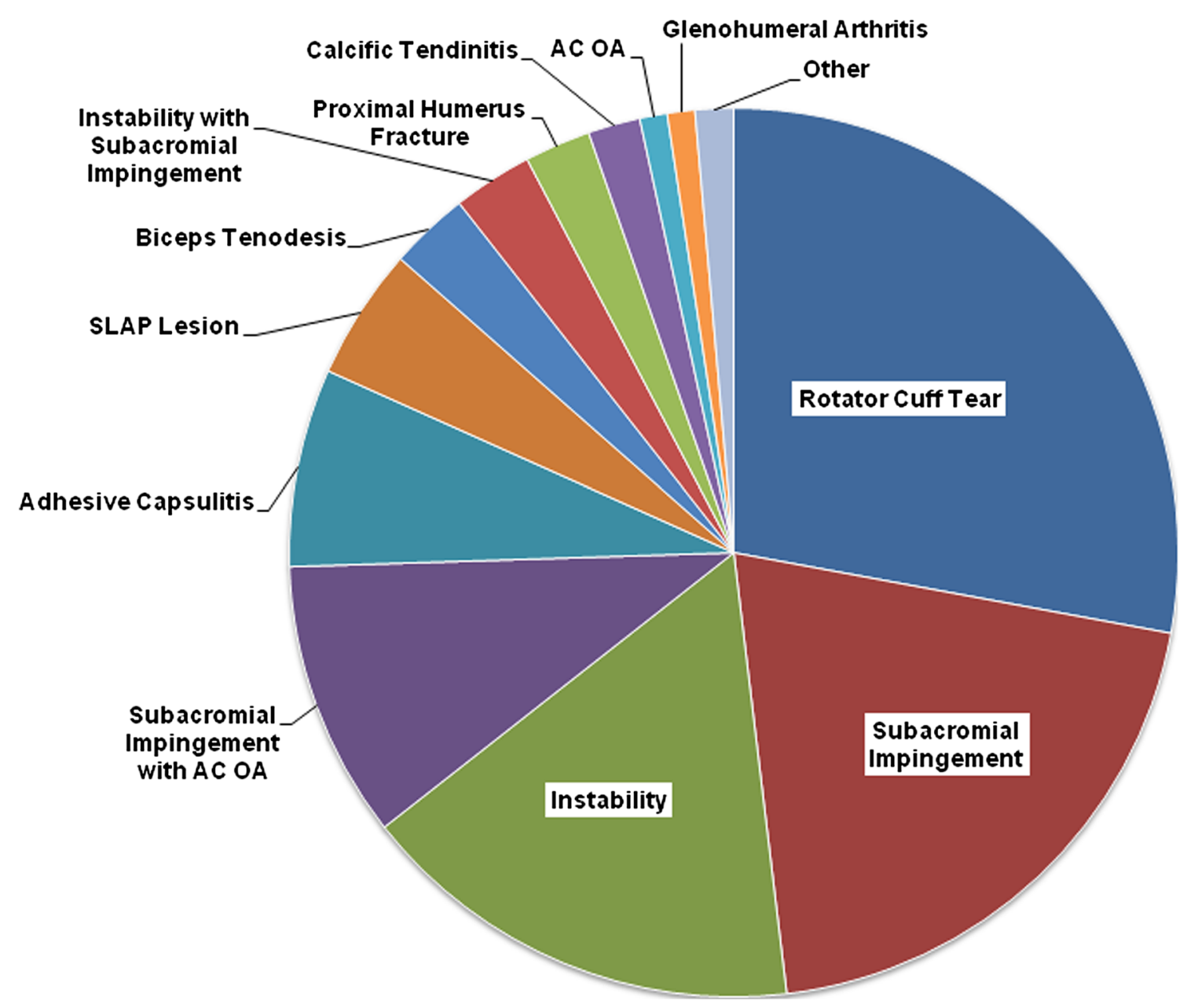

Fig. 1 Percent of injected patients' diagnoses [number males + females in each diagnostic category, as shown in the left-half of Table 1, divided by the total number of

surgery for a proximal humerus fracture (24\% of 21 patients injected) (Table 1 columns C, D).

Of the 208 injected cases, $8(4 \%)$ were insulin-dependent diabetics, 15 (7\%) were non-insulin diabetics, 110 (53\%) were female, and 98 (47\%) were male. The average age and BMI for patients receiving a corticosteroid injection were $46 \pm 14$ (years) and $28.7 \pm 6.1$ $\left(\mathrm{kg} / \mathrm{m}^{2}\right)$, respectively. The general reasons for the injection, as determined by the senior author's assessment, were: pain (63\%), stiffness (24\%), and "bursitis/inflammation" (13\%). The percentage of patients receiving an injection injections $(n=208)]$. $A C$ acromioclavicular, $G H$ glenohumeral, $O A$ osteoarthritis

and their diagnoses are summarized in Figs. 1, 2 and Table 1.

We found significant differences $(p \leq 0.03)$ between patients who did and who did not receive corticosteroid injections with respect to sex (injected patients were more commonly female) and age (younger patients were more commonly injected after rotator cuff repair) (Table 2). There were no significant differences with respect to arthroscopic vs. open surgery, BMI, or any of the other patient characteristics.

Regardless of age, sex, or diagnosis, nearly $95 \%$ of the patients (response rate 97\%) 


\section{Percent of Patients who Received a Corticosteroid Injection and Their Diagnoses}

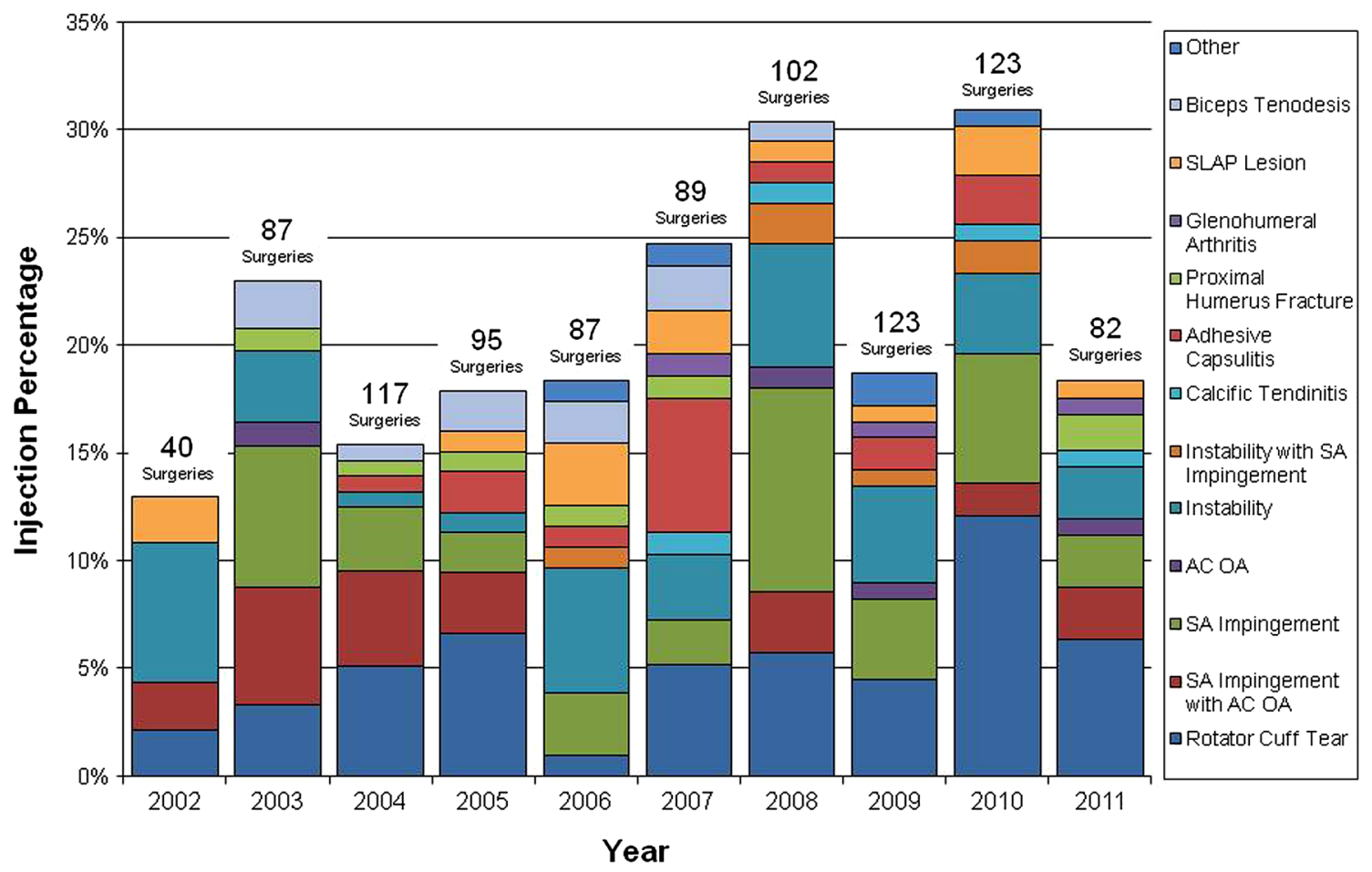

Fig. 2 Percent of patients in each year who received a corticosteroid injection and their diagnoses. $A C$ acromioclavicular, $S A$ subacromial, $G H$ glenohumeral, $O A$

reported at least mild-to-moderate improvement in pain and function between 4 and 6 weeks after the injections. By 8-12 weeks after the injections, the reports of improvements had diminished, but unfortunately the compliance in completing the questionnaire was only $79 \%$. None of the injections were associated with major or minor complications, including no infections, poor wound healing, dermatitis, or any other apparent compromise of the surgery (e.g., no association with tendon or ligament ruptures or injuries). There were no reports that the injection(s) made symptoms worse.

There were seven cases where corticosteroid injections were given within 21 days of surgery. The reason for the majority of these "early" injections was that these patients had high likelihood of developing significant/recurrent stiffness. All of these cases involved osteoarthritis. Other less frequent diagnoses include: AC separation, heterotopic ossification, pectoralis rupture, and fractures

arthroscopic capsular releases for primary adhesive capsulitis.

In the series of 945 surgeries, there were 25 instances (3\%) where it was recommended that the patient have a shoulder corticosteroid injection but refused to have it. Instead of receiving injections, 13 of these patients agreed to take an oral corticosteroid on a 1-week tapered dosing schedule (methylprednisolone tablets; Medrol ${ }^{\circledR}$ dose pack; Pfizer Inc., NY, USA). Similar to the injections, this course was given between 3 weeks and 6 months after their shoulder surgery as a means for treating their shoulder stiffness and pain. The remaining 12 patients gave various reasons for refusing the injection or oral corticosteroids, including eight patients stating that they simply did not want "a shot" because of their concern of incurring high pain and/or they did not want any 
"steroids," reflecting the concern that they could have untoward consequences [28]. The remaining four patients were concerned with other potential adverse reactions, including flushing or allergic reactions. None of these 25 patients who refused the recommended injection subsequently had a corticosteroid injection within 6 months of their shoulder surgery. Additionally, these 25 patients were not included in the analysis of patients who received injections.

Of the 208 patients who received a corticosteroid injection, 53 patients (25\%) required a second injection within the 6-month study period. Of the patients requiring two injections, 30 were female and 23 were male, and the average age was $43.2 \pm 13.4$ years. Pain was the most common reason for injecting a second time $(70 \%)$, followed by stiffness (24\%) and "bursitis/inflammation" (6\%).

\section{DISCUSSION}

In our series of 945 shoulder surgeries on 754 patients, we found that the overall frequency with which corticosteroid injections were given within 6 months after the various non-arthroplasty surgeries was $22 \%$ (208/945 surgeries). These injections were given to enhance functional recovery and increase overall comfort in patients who were experiencing excessive pain and/or stiffness that was impeding their progress in physiotherapy. We have also found our results to be helpful in our daily practice of orthopedics because it provides data that help inform our patients prior to their shoulder surgeries of the possibility that a shoulder corticosteroid injection could be given to enhance their postoperative recovery. For example, during preoperative consultation the senior author uses these data to routinely advise his patients that there is approximately a one-in-five chance that a corticosteroid injection will be administered within a few months after their shoulder surgery as a means to enhance their recovery. This provides patients with the comfort of knowing prospectively that the administration of corticosteroid injections is viewed as a useful adjunct to physiotherapy in the postoperative setting for some patients and gives them the opportunity to mentally prepare for the possibility of this treatment modality.

The presumed effectiveness that corticosteroid injections have in treating postoperative shoulder pain and stiffness was primarily based on studies that were not conducted in the postoperative setting. The favorable results of many of these previous studies suggest that significant relief of pain and stiffness would also be gained, at least in the short term, in postoperative patients. For example, two recent studies show the effectiveness of corticosteroid injections in the postoperative setting after arthroscopic rotator cuff repair $[29,30]$. One of these studies found significant short-term effectiveness after their patients were injected at the time of surgery with corticosteroid into the glenohumeral joint in the treatment group vs. isotonic saline in a control group (50 total patients were studied) [30]. However, in that study, pain was only evaluated up to $24 \mathrm{~h}$ after the injection, which limits comparisons with our results. The other study is more applicable in terms of drawing comparisons with our data set. It that study, Shin et al. [29] evaluated 72 of 458 patients who received subacromial injections ( $16 \%$ injection rate) within 8 weeks of surgery because of severe pain. They found that pain measured on a visual analog scale remained significantly lower at 3 months after the injection was given. However, at that time the patients' functional outcomes were not significantly different from the group that was not injected. They found that preoperative stiffness was a predisposing factor for persistent pain (odds ratio, $0.2 ; p=0.04$ ). This factor was not evaluated in the present study and warrants additional study among the various types of shoulder surgeries that we evaluated.

As a standard practice in the senior author's clinic, corticosteroid injections are not given until 21 days after shoulder surgery even if there was no repair or reconstruction of injured structures. In very few of our cases were corticosteroid injections given within 21 days of surgery, and in these cases there was high likelihood of the rapid development of stiffness (i.e., mostly in cases of primary adhesive capsulitis, as described further below). In cases 
where there was surgical repair or reconstruction, we did not give corticosteroid injections within 12 weeks of surgery. The basis for these injection guidelines included studies of the effects of corticosteroids that found that: (1) corticosteroids inhibit collagen synthesis [31, 32], and (2) at approximately 21 days post-operation, collagen synthesis is nearing completion and rapid removal and new collagen deposition occur simultaneously [33]. Based on these and other studies [34, 35], which were all prior to the 10-year study period, it was concluded these time intervals allowed for adequate time for healing in relation to the spectrum of surgeries and diagnoses that might be considered for postoperative corticosteroid injections.

Our findings support the hypothesis that patients with calcific tendinitis $(40 \%$ of these patients were injected), rotator cuff tears (19\%), and glenohumeral instability (16\%) are among the most likely preoperative diagnoses to receive a postoperative corticosteroid injection (Table 2). Although $20 \%$ of insulin-dependent and non-insulin dependent diabetics combined received corticosteroid injections, this rate is not different from that of non-diabetic patients $(22 \%$ of these patients were injected). This result does not indicate a higher rate of diabetic patients refusing corticosteroid injections because of the potential risk of these injections to cause elevated blood glucose levels.

Patients with SLAP lesions and calcific tendinitis were the most commonly injected groups in terms of relative percentage of cases injected within a specific diagnostic/surgery group (40\% in each group; $4 / 10$ calcific tendinitis; 10/25 SLAP lesions). Calcific tendinitis typically presents with severe, disabling pain, which occurs spontaneously. There can be concomitant stiffness, giving rise to a clinical picture that resembles adhesive capsulitis $[36,37]$. Corticosteroid injections are often used in the nonoperative management of this condition $[38,39]$, which suggests that they can be similarly used in the postoperative setting.

Patients with subacromial impingement were also among the most commonly injected (28\%). Reasons for this might include: (1) the bursectomy performed in these cases causes increased inflammation and bleeding, which can lead to stiffness and pain [40], and (2) nearly one-half of these cases were done with a mini-open incision, which could produce postoperative stiffness as is seen with mini-open rotator cuff repairs. Severud et al. [21] reported a comparative outcome analysis between their arthroscopic and mini-open rotator cuff repairs and found a 14\% incidence of postoperative adhesions and stiffness in the mini-open group and a $0 \%$ incidence in the arthroscopic group. Consequently, it is not surprising that patients with rotator cuff repairs were commonly injected. In fact, a recent literature review by Papalia et al. [41] shows that excessive postoperative stiffness after rotator cuff repair can occur in up to $33 \%$ of cases. In turn, patients with shoulder stiffness require a longer period of time to achieve postoperative return of function, and patients with severe preoperative stiffness have a higher rate of poor outcomes after rotator cuff repair $[42,43]$.

The capsular shift procedure for glenohumeral instability is a surgery/diagnosis that was relatively commonly injected (16\%) in our series. These procedures can result in excessive limitation of motion that can cause discomfort for patients [4, 44]. For example, Antoniou et al. [19] state that $68 \%$ of patients in their study perceived stiffness after capsulolabral augmentation. In a study of ten patients who had internal rotation contracture after anterior repair for recurrent dislocation of the shoulder, MacDonald et al. [45] reported that all the patients received pain relief and attained an average increase of 27 degrees of rotation after subscapularis tendon release. Although corticosteroid injections seem to have potential in helping to avoid surgical lysis of contractures in these cases, studies of the effectiveness of corticosteroid injections in this context are also lacking.

The reasons for why repairs of SLAP lesions had the highest rate of postoperative injections $(40 \%)$ are less clear but likely are related to the reasons given above for capsular shift and subacromial impingement procedures. This is because SLAP repairs involve repair of the glenoid labrum, which is in close proximity to the 
glenohumeral capsule and involves instruments being passed through the subacromial region.

Conditions such as bicipital tenosynovitis, glenohumeral and acromioclavicular arthritis, and rotator cuff tears can also lead to a stiff and painful shoulder, which can mimic adhesive capsulitis [22, 36, 46]. But patients with these diagnoses do not have true capsular contracture and restrictions in passive range of motion and therefore do not have primary adhesive capsulitis. Primary adhesive capsulitis may be related to immunological, biochemical, or hormonal imbalances and is diagnosed when no findings on history or examination can explain the onset of the adhesive capsulitis symptoms $[22,46]$. Secondary adhesive capsulitis develops from stiffness and immobility from previous shoulder trauma or surgery and may represent an entirely different condition from primary adhesive capsulitis. Most of our 51 cases with this diagnosis had secondary adhesive capsulitis, where their stiffness and immobility were due to excessive postoperative stiffness from trauma or a previous shoulder surgery, and this was a diagnosis for which patients commonly received postoperative corticosteroid injections (29\%). Although studies of the efficacy of corticosteroid injections in treating this condition show highly variable outcomes, there are benefits in the short term in terms of pain relief. We hypothesize that it is primarily pain relief that enhances progress in physiotherapy when patients with this problem receive both subacromial and glenohumeral corticosteroid injections [17, 47].

In our series of patients, we did not expect the observed lack of differences in injection rates for open vs. arthroscopic procedures in view of prior studies suggesting that open procedures incur higher rates of postoperative stiffness [2, 21, 41, 48]. However, we subsequently became aware of other studies showing that stiffness can be common after arthroscopic shoulder procedures [48-50] and that the pain after arthroscopic and open rotator cuff repairs is similar [51].

The fact that women were more likely than men to receive a corticosteroid injection was also not anticipated. This might reflect a sex-related difference in the report of pain intensity. This phenomenon has been observed in several trials studying these potential differences [52-54]. This issue, as well as the finding that younger patients with rotator cuff repairs had higher rates of injections, warrants additional study to determine the reasons for these findings $[55,56]$. The number of patients in the calcific tendinitis group $(n=10)$ was insufficient for detecting the possibility of differences in patient characteristics including age and sex. By contrast, there were 25 patients in the SLAP repair group, which did not have differences in patient characteristics and an equally high rate of injection compared to calcific tendinitis.

Major and minor complications resulting from shoulder corticosteroid injections are reviewed by Gruson et al. [5]. One of the major risks is the potential for causing an infection from the corticosteroid injection. There were no infections in any of the patients in our study, which suggests that our skin prep with alcohol followed by povidone-iodine is sufficient.

Limitations of our study include the lack of evaluator blinding, which can introduce bias, and a main outcome measure (symptom changes) was only assessed in the intervention (injection) group with no similar follow-up of a control (no injection) group. Each surgery was also analyzed as an independent entity and without any particular consideration for potential inter-subject variation in baseline pain perception or pre-existing propensity for shoulder stiffness in all patients (not just in those with adhesive capsulitis). Future studies that are designed to address these limitations and related issues that are inherent in retrospective studies are needed in order to determine the effectiveness of these injections in enhancing functional recovery after non-arthroplasty shoulder surgeries.

\section{CONCLUSIONS}

Our 10-year retrospective view of the senior author's practice shows that approximately one in five patients (22\%) received a subacromial and/or glenohumeral corticosteroid injection within 6 months following their 
non-arthroplasty shoulder surgery. Among the diagnoses with more than ten patients who had the highest percentages of patients who received an injection were calcific tendinitis (40\%), SLAP lesions (40\%), adhesive capsulitis (29\%), subacromial impingement (28\%), proximal humerus fracture $(24 \%)$, rotator cuff tear (19\%), and glenohumeral instability (16\%). There were no significant differences with respect to arthroscopic vs. open surgery, BMI, or any of the other patient characteristics. In addition to achieving the main goal of establishing our frequency of shoulder corticosteroid injections in the postoperative setting, the present study also provides valuable information for incorporating their use into physiotherapy protocols that can be systematically studied. These future studies must have alternative treatment groups and serial follow-up visits with validated outcome measures. The present study represents an important first step toward achieving these broader goals.

\section{ACKNOWLEDGEMENTS}

No external funding or sponsorship was received for this study or publication of this article. The authors thank Dr. Kenneth J. Hunt for his criticisms of the manuscript and Mr. Jake Reynolds for assistance with data acquisition. All named authors meet the International Committee of Medical Journal Editors (ICMJE) criteria for authorship for this manuscript, take responsibility for the integrity of the work as a whole, and have given final approval to the version to be published.

Disclosures. John G. Skedros, Micheal G. Adondakis, Alex N. Knight, and Michael B. Pilkington declare that they have no conflicts of interest.

Compliance with Ethics Guidelines. This study was reviewed and approved by the Ethics Committee of Intermountain Healthcare (no. 1024079, Salt Lake City, Utah). All procedures followed were in accordance with the Helsinki Declaration of 1964, as revised in 2013. The analysis used anonymous clinical data that were obtained after each patient agreed to treatment by written consent. Because the study is retrospective, patients were not aware that data related to their treatment and management would be used for this study. For full disclosures, the details of the study are available from Intermountain Healthcare Institutional Review Board (see Data Availability section below).

Data Availability. The data sets during and/ or analyzed during the current study are available from the corresponding author on reasonable request.

Open Access. This article is distributed under the terms of the Creative Commons Attribution-NonCommercial 4.0 International License (http://creativecommons.org/licenses/ by-nc/4.0/), which permits any noncommercial use, distribution, and reproduction in any medium, provided you give appropriate credit to the original author(s) and the source, provide a link to the Creative Commons license, and indicate if changes were made.

\section{REFERENCES}

1. Salerno A, Hermann R. Efficacy and safety of steroid use for postoperative pain relief. Update and review of the medical literature. J Bone Jt Surg Am. 2006;88(6):1361-72.

2. Huberty DP, Schoolfield JD, Brady PC, Vadala AP, Arrigoni P, Burkhart SS. Incidence and treatment of postoperative stiffness following arthroscopic rotator cuff repair. Arthroscopy. 2009;25(8):880-90.

3. Cole BJ, Schumacher HR Jr. Injectable corticosteroids in modern practice. J Am Acad Orthop Surg. 2005;13(1):37-46.

4. Kang RW, Frank RM, Nho SJ, Ghodadra NS, Verma $\mathrm{NN}$, Romeo AA, et al. Complications associated with anterior shoulder instability repair. Arthroscopy. 2009;25(8):909-20.

5. Gruson KI, Ruchelsman DE, Zuckerman JD. Subacromial corticosteroid injections. J Shoulder Elb Surg. 2008;17(1 Suppl):118S-30S.

6. Alvarez CM, Litchfield R, Jackowski D, Griffin S, Kirkley A. A prospective, double-blind, randomized 
clinical trial comparing subacromial injection of betamethasone and xylocaine to xylocaine alone in chronic rotator cuff tendinosis. Am J Sports Med. 2005;33(2):255-62.

7. Koester MC, Dunn WR, Kuhn JE, Spindler KP. The efficacy of subacromial corticosteroid injection in the treatment of rotator cuff disease: a systematic review. J Am Acad Orthop Surg. 2007;15(1):3-11.

8. Arroll B, Goodyear-Smith F. Corticosteroid injections for painful shoulder: a meta-analysis. Br J Gen Pract. 2005;55(512):224-8.

9. Blair B, Rokito AS, Cuomo F, Jarolem K, Zuckerman JD. Efficacy of injections of corticosteroids for subacromial impingement syndrome. J Bone Jt Surg Am. 1996;78(11):1685-9.

10. Plafki C, Steffen R, Willburger RE, Wittenberg RH. Local anaesthetic injection with and without corticosteroids for subacromial impingement syndrome. Int Orthop. 2000;24(1):40-2.

11. Lorbach O, Anagnostakos K, Scherf C, Seil R, Kohn D, Pape D. Nonoperative management of adhesive capsulitis of the shoulder: oral cortisone application versus intra-articular cortisone injections. J Shoulder Elb Surg. 2010;19(2):172-9.

12. Rhon DI, Boyles RB, Cleland JA. One-year outcome of subacromial corticosteroid injection compared with manual physical therapy for the management of the unilateral shoulder impingement syndrome: a pragmatic randomized trial. Ann Intern Med. 2014;161(3):161-9.

13. Skedros JG, Hunt KJ, Pitts TC. Variations in corticosteroid/anesthetic injections for painful shoulder conditions: comparisons among orthopaedic surgeons, rheumatologists, and physical medicine and primary-care physicians. BMC Musculoskelet Disord. 2007;8:63.

14. Skedros JG, Pitts TC. Corticosteroids for painful shoulder conditions: injection techniques. J Musculoskelet Med. 2008;25(8):1-14.

15. Skedros JG, Pitts TC. Injectable corticosteroids for the painful shoulder: patient evaluation. J Muscluoskelet Med. 2008;25(5):1-12.

16. Skedros JG, Pitts TC. The use and misuse of injectable corticosteroids for the painful shoulder. J Musculoskelet Med. 2008;25(2):78-96.

17. Skedros JG, Pitts TC. Temporal variations in a modified Neer impingement test can confound clinical interpretation. Clin Orthop Relat Res. 2007;460:130-6.
18. Matsuki K, Sugaya H. Complications after arthroscopic labral repair for shoulder instability. Curr Rev Musculoskelet Med. 2015;8(1):53-8.

19. Antoniou J, Duckworth DT, Harryman DT 2nd. Capsulolabral augmentation for the management of posteroinferior instability of the shoulder. J Bone Jt Surg Am. 2000;82(9):1220-30.

20. Chen AL, Shapiro JA, Ahn AK, Zuckerman JD, Cuomo F. Rotator cuff repair in patients with type I diabetes mellitus. J Shoulder Elb Surg. 2003;12(5):416-21.

21. Severud EL, Ruotolo C, Abbott DD, Nottage WM. All-arthroscopic versus mini-open rotator cuff repair: a long-term retrospective outcome comparison. Arthroscopy. 2003;19(3):234-8.

22. Neviaser AS, Neviaser RJ. Adhesive capsulitis of the shoulder. J Am Acad Orthop Surg. 2011;19(9):536-42.

23. Wilk KE, Harrelson GL, Arrigo C, Chmielewski T. Shoulder rehabilitation. In: Andrews JR, Harrelson GL, Wilk KE, editors. Physical rehabilitation of the injured athlete. 2nd ed. Philadelphia: W.B. Saunders and Co; 1998. p. 478-553.

24. Breivik EK, Bjornsson GA, Skovlund E. A comparison of pain rating scales by sampling from clinical trial data. Clin J Pain. 2000;16(1):22-8.

25. Sokal RR, Rohlf FJ. Biometry. In: Wilson J, Cotter S, editors. The principles and practice of statistics in biological research. 3rd ed. New York: W.H. Freeman and Co; 1995.

26. Hintze J. Number Cruncher Statistical Systems 6.0 User's Manual. Kaysville; 1995.

27. Siegel S, Castellan NJ Jr. Nonparametric statistics for the behavioral sciences. 2nd ed. New York: McGraw-Hill; 1988.

28. Kromer TO, Sieben JM, de Bie RA, Bastiaenen $\mathrm{CH}$. Influence of fear-avoidance beliefs on disability in patients with subacromial shoulder pain in primary care: a secondary analysis. Phys Ther. 2014;94(12):1775-84.

29. Shin SJ, Do NH, Lee J, Ko YW. Efficacy of a subacromial corticosteroid injection for persistent pain after arthroscopic rotator cuff repair. Am J Sports Med. 2016;44(9):2231-6.

30. Perdreau A, Joudet T. Efficacy of multimodal analgesia injection combined with corticosteroids after arthroscopic rotator cuff repair. Orthop Traumatol Surg Res. 2015;101(8 Suppl):S337-45. 
31. Shull S, Cutroneo KR. Glucocorticoids coordinately regulate procollagens type I and type III synthesis. J Biol Chem. 1983;258(5):3364-9.

32. Lenco W, McKnight M, Macdonald AS. Effects of cortisone acetate, methylprednisolone and medroxyprogesterone on wound contracture and epithelization in rabbits. Ann Surg. 1975;181(1):67-73.

33. Madden JW, Peacock EE Jr. Studies on the biology of collagen during wound healing. 3. Dynamic metabolism of scar collagen and remodeling of dermal wounds. Ann Surg. 1971;174(3):511-20.

34. Fleischli JW, Adams WR. Use of postoperative steroids to reduce pain and inflammation. J Foot Ankle Surg. 1999;38(3):232-7.

35. Hanna JR, Giacopelli JA. A review of wound healing and wound dressing products. J Foot Ankle Surg. 1997;36(1):2-14 discussion 79.

36. De Carli A, Pulcinelli F, Rose GD, Pitino D, Ferretti A. Calcific tendinitis of the shoulder. Joints. 2014;2(3):130-6.

37. Chen SK, Chou PH, Lue YJ, Lu YM. Treatment for frozen shoulder combined with calcific tendinitis of the supraspinatus. Kaohsiung J Med Sci. 2008;24(2):78-84.

38. Ogon P, Suedkamp NP, Jaeger M, Izadpanah K, Koestler W, Maier D. Prognostic factors in nonoperative therapy for chronic symptomatic calcific tendinitis of the shoulder. Arthritis Rheum. 2009;60(10):2978-84.

39. Yoo JC, Koh KH, Park WH, Park JC, Kim SM, Yoon YC. The outcome of ultrasound-guided needle decompression and steroid injection in calcific tendinitis. J Shoulder Elb Surg. 2010;19(4):596-600.

40. Guyette TM, Bae H, Warren RF, Craig E, Wickiewicz TL. Results of arthroscopic subacromial decompression in patients with subacromial impingement and glenohumeral degenerative joint disease. J Shoulder Elb Surg. 2002;11(4):299-304.

41. Papalia R, Franceschi F, Vasta S, Gallo A, Maffulli N, Denaro V. Shoulder stiffness and rotator cuff repair. Br Med Bull. 2012;104:163-74.

42. Tauro JC. Stiffness and rotator cuff tears: incidence, arthroscopic findings, and treatment results. Arthroscopy. 2006;22(6):581-6.

43. Cho CH, Jang HK, Bae KC, Lee SW, Lee YK, Shin $\mathrm{HK}$, et al. Clinical outcomes of rotator cuff repair with arthroscopic capsular release and manipulation for rotator cuff tear with stiffness: a matched-pair comparative study between patients with and without stiffness. Arthroscopy. 2015;31(3):482-7.

44. Hawkins RH, Hawkins RJ. Failed anterior reconstruction for shoulder instability. J Bone Jt Surg Br. 1985;67(5):709-14.

45. MacDonald PB, Hawkins RJ, Fowler PJ, Miniaci A. Release of the subscapularis for internal rotation contracture and pain after anterior repair for recurrent anterior dislocation of the shoulder. J Bone Jt Surg Am. 1992;74(5):734-7.

46. Hsu JE, Anakwenze OA, Warrender WJ, Abboud JA. Current review of adhesive capsulitis. J Shoulder Elb Surg. 2011;20(3):502-14.

47. Oh JH, Oh $\mathrm{CH}$, Choi JA, Kim SH, Kim JH, Yoon JP. Comparison of glenohumeral and subacromial steroid injection in primary frozen shoulder: a prospective, randomized short-term comparison study. J Shoulder Elb Surg. 2011;20(7):1034-40.

48. Parsons BO, Gruson KI, Chen DD, Harrison AK, Gladstone J, Flatow EL. Does slower rehabilitation after arthroscopic rotator cuff repair lead to long-term stiffness? J Shoulder Elb Surg. 2010;19(7):1034-9.

49. Brislin KJ, Field LD, Savoie FH 3rd. Complications after arthroscopic rotator cuff repair. Arthroscopy. 2007;23(2):124-8.

50. Vezeridis PS, Goel DP, Shah AA, Sung SY, Warner JJ. Postarthroscopic arthrofibrosis of the shoulder. Sports Med Arthrosc. 2010;18(3):198-206.

51. Pham TT, Bayle Iniguez X, Mansat P, Maubisson L, Bonnevialle N. Postoperative pain after arthroscopic versus open rotator cuff repair. A prospective study. Orthop Traumatol Surg Res. 2016;102(1):13-7.

52. Stiglitz Y, Gosselin O, Sedaghatian J, Sirveaux F, Mole D. Pain after shoulder arthroscopy: a prospective study on 231 cases. Orthop Traumatol Surg Res. 2011;97(3):260-6.

53. Bartley EJ, King CD, Sibille KT, Cruz-Almeida Y, Riley JL 3rd, Glover TL, et al. Enhanced pain sensitivity among individuals with symptomatic knee osteoarthritis: potential sex differences in central sensitization. Arthritis Care Res (Hoboken). 2016;68(4):472-80.

54. Bement MH, Drewek B, Hunter SK. Men report greater pain relief following sustained static contractions than women when matched for baseline pain. J Mot Behav. 2014;46(2):107-13.

55. Gagliese L, Weizblit N, Ellis W, Chan VW. The measurement of postoperative pain: a comparison 
of intensity scales in younger and older surgical patients. Pain. 2005;117(3):412-20.

56. Herr KA, Spratt K, Mobily PR, Richardson G. Pain intensity assessment in older adults: use of experimental pain to compare psychometric properties and usability of selected pain scales with younger adults. Clin J Pain. 2004;20(4):207-19. 